\title{
Reactions coupled to palladium
}

\author{
You would be forgiven if you thought the most important element in an organic transformation was \\ carbon. Matthew Hartings argues that, for just over half a century in many of chemistry's most renowned \\ organic reactions, it has actually been palladium.
}

T he science of palladium gained fame beyond the industrial and chemical communities in 2010, when Richard Heck, Ei-ichi Negishi and Akira Suzuki received the Nobel Prize in recognition of their development of palladium-catalysed carbon-carbon bond formation. Their reactions, and the many similar ones that they inspired, have had a profound impact on the way chemists make molecules that are used in a diverse array of products, from industrial materials to pharmaceuticals. In addition, palladium has been used as a catalyst in the Wacker process - regarded as the first industrially applied organometallic reaction - for the past fifty years.

Intriguing questions arise: Why palladium? What is it that makes the metal such a great catalyst for these processes? And when did chemists begin to realize that this was the case?

Among transition metals, good catalysts are those unsaturated ones with open coordination sites. Palladium(II) is one of several metal ions with $d^{8}$ electron configurations that tend to adopt squareplanar geometries - which, conveniently, have two empty axial coordination sites.

More importantly, to run the reactions involved with the Wacker process and Heck/Sonogashira-type couplings, a metal catalyst must be able to associate with a carbon-carbon double bond ${ }^{1}$. It turns out that nickel, palladium and platinum all have the proper orbital energies to be able to do this. Platinum, however, is a poor catalyst, in part because the kinetics of olefin-Pt bond formation are slow ${ }^{1}$. Several nickel complexes do show catalytic activity towards olefin reactions ${ }^{1}$, but it is palladium that continues to forge its way as the metal centre of many successful olefin catalysts.

Palladium certainly has some unique characteristics. Its ground-state electronic structure is $4 d^{10} 5 s^{0}$, making it the only transition metal to combine a filled $d$ orbital with an empty frontier $s$ orbital. Also, palladium's lowest $d$ to $p$ transition is decidedly larger in energy than the equivalent transition for similar metals ${ }^{2}$. These two facts seem to indicate that its catalytic activity occurs mainly through its $4 d$ electrons, with low percentages of hybridization from the $5 s$ and $5 p$ orbitals, and surely play some role in making palladium 'just right' in olefin reaction catalysis.

By the time Heck's original paper on carbon-carbon coupling reactions appeared, the value of palladium as a catalyst for olefin reactions was already established ${ }^{3}$. This is, in part, due to the work of Smidt et al. in their development of the Wacker process, first using platinum, then palladium three years later ${ }^{4}$. But the history of palladium-based olefin oxidation goes back further than this. The initial publication of the Wacker process referenced an article from $1894^{5}$, by Francis C. Phillips, as the first observation of the ability of palladium to catalyse the oxidation of olefins.

Phillips was an expert on the reactions of gases in the late 1800s, at Western University (currently known as the University of Pittsburgh). He had received funding to identify the components of gases mined in Western Pennsylvania, and to do this needed to understand the physical and chemical characteristics of the individual gases that might be present in the mined gas mixture.

Phillips set out to study the way different gases are oxidized by air in the presence of various metals and their chloride salts ${ }^{5,6}$ - a two-part study that is impressive in terms of both experimental effort and sheer scope. In the first stage, he attempted to quantify the oxidation of gases over different metals dispersed in asbestos fibres ${ }^{6}$. In the second, he aimed to describe these reactions qualitatively, by bubbling the gases through solutions containing metal salts 5 . For this, he tested twenty different gases and nineteen different catalysts.

It is in this second study that Phillips describes the reactions of olefins over palladium chloride. For the case of ethylene, he writes, "Quickly reduced, the metal appearing as a black powder. No carbon dioxide is formed"s. So, he understood that the gas was being oxidized over palladium, and that the oxidation product was not $\mathrm{CO}_{2}$. Had he been able to isolate and characterize acetaldehyde, he would have had described the substantive chemistry of the Wacker process I think it is important to note here that Phillips was not looking for industrially important reactions in his experiments; he was just trying to better understand chemistry. In what may be the most understated line in the paper that would set the framework for the Wacker process and Heck/Sonogashira couplings, he concludes his report by writing, "To be continued."

\section{MATTHEW R. HARTINGS is at the} Department of Chemistry, College of Arts and Science, American University, 4400 Massachusetts Ave, NW, Washington, DC 20016, USA.

e-mail: hartings@american.edu

\footnotetext{
References

1. Collman, J. P., Hegedus, L. S., Norton, J. R. \& Rinke, R. G. Principles and Applications of Organotransition Metal Chemistry Ch. 14 (University Science Books, 1987).

2. Moore, C. E. Atomic Energy Levels, Vol. III (Molybdenum through Lanthanum and Hafnium through Actinium) (Circular of the National Bureau of Standards 467, US Government Printing Office, 1958)

3. Heck, R. F. J. Am. Chem. Soc. 90, 5518-5526 (1968).

4. Smidt, J. et al. Angew. Chem. Int. Ed. 1, 80-88 (1962).

5. Phillips, F. C. Am. Chem. J. 16, 255-276 (1894).

6. Phillips, F. C. Am. Chem. J. 16, 163-187 (1894).
} 